\title{
Z BADAŃ NAD OBECNOŚCIĄ SKANDYNAWÓW NA POLUDNIOWYM WYBRZEŻU BALTYKU W POCZĄTKACH ŚREDNIOWIECZA
}

\author{
RESEARCH INTO SCANDINAVIAN PRESENCE \\ AT THE SOUTHERN SHORE OF THE BALTIC \\ IN THE EARLY MIDDLE AGES
}

\begin{abstract}
Interdisciplinary research into Scandinavian presence in the Slavic domain at the southern shore of the Baltic in the early Middle Ages has provided new data conducive to reconstruction of the natural and cultural landscapes.
\end{abstract}

Keywords: southern shore of the Baltic, early Middle Ages, Scandinavians, craft and trade emporia, interdisciplinary research.

Wieloaspektowe badania interdyscyplinarne prowadzone $\mathrm{w}$ ostatnich latach na południowym wybrzeżu Bałtyku dostarczyły nowych interesujących wyników związanych z rekonstrukcją krajobrazu przyrodniczego i kulturowego we wczesnym średniowieczu. W strefie przybrzeżnej w VII-VIII wieku powstawały i funkcjonowały wyspecjalizowane $\mathrm{w}$ rzemiośle i wymianie towarowej osady tworzące ponadregionalną sieć powiązań pomiędzy Skandynawią a Europą Środkową. Być może niektóre $\mathrm{z}$ nich zostały założone na obszarze słowiańskim przez ludność skandynawską. Wyniki studiów nad wczesnośredniowieczną kulturą materialną i praktykami pogrzebowymi pozwalają przypuszczać, że w rezultacie procesu akulturacji ukształtowały się heterogeniczne społeczności tworzące wokół Bałtyku specyficzne centra wytwarzania i dystrybucji różnorodnych dóbr pożądanych w różnych rejonach ówczesnego świata. Dane pozyskane metodami archeologicznymi potwierdziły i uzupełniły informacje zawarte w skąpych źródłach pisanych. W świetle wyników badań nad dziejami geologicznymi i kulturowymi obszarów nadbałtyckich można stwierdzić, że Morze Bałtyckie od pradziejów stanowiło bardziej po-

\footnotetext{
${ }^{*}$ Hauke Jöns: Lower Saxony Institute for Historical Coastal Research, Wilhelmshaven. Anna B. Kowalska: Ośrodek Archeologii Średniowiecza Krajów Nadbałtyckich, IAE PAN.
} 
most niż barierę w kontaktach pomiędzy społecznościami zamieszkującymi w części południowej i północnej.

Prowadzone w ostatnich latach interdyscyplinarne badania nad schyłkiem starożytności i początkami średniowiecza nad Bałtykiem przyniosły szereg interesujących wyników pozwalających na weryfikację niektórych dotychczasowych ustaleń. W badaniach nad rozwojem wczesnośredniowiecznego osadnictwa w strefie nadbałtyckiej, w świetle badań nad paleogeografią i zmianami klimatycznymi, należy uwzględnić kilka istotnych czynników, takich jak wahania poziomu morza powodujące cofanie się linii brzegowej, stała erozja przybrzeżnej części lądu, zamulanie zatok i ujść rzek odgrywających rolę ważnych wodnych dróg komunikacyjnych. Generalnie uwaga ta dotyczy całego wybrzeża słowiańskiego pomiędzy Limes Saxoniae a ujściem Wisły, chociaż istnieją znaczące różnice pomiędzy częściami wschodnią i zachodnią, i oznacza bezpowrotną utratę możliwości rozpoznania przebiegu i skali niektórych procesów kulturowych (Jöns 2011).

Etnogeneza i okoliczności migracji Słowian na obszary południowego Bałtyku od dawna pozostają tematem budzącym kontrowersje. W literaturze przedmiotu ścierają się różne opinie. Zdaniem części badaczy Słowianie pojawili się w basenie Morza Bałtyckiego w VI-VII stuleciu (Leciejewicz 2000, s. 144-175), gdzie mieli zetknąć się z pozostałą na tych obszarach ludnością germańską (Mangelsdorf 2001; Schoknecht 2001, s. 511-513). Inna teoria, wsparta badaniami nad materiałem archeologicznym i dendrodatowaniami zakłada, że Słowianie rozpoczęli kolonizację obszarów nadmorskich nie wcześniej niż w 2. połowie VII w., zajmując tereny opuszczone przez poprzednich mieszkańców w połowie VI stulecia (Dulinicz 2001, s. 206-213). Argumentów w tej dyskusji dostarczają ostatnio między innymi wyniki badań palinologicznych. W ich świetle osłabienie osadnictwa na Pomorzu w okresie wędrówek ludów jest bardzo wyraźne, ale w próbach z tego okresu przez cały czas zaznacza się obecność pyłku zbóż, co świadczy o funkcjonowaniu niewielkich grup ludności na tym obszarze (Latałowa 2017). Próby pobrane we wschodniej części Holsztynu także ukazały znaczne ograniczenie osadnictwa w VI i VII w., znacząco zwiększył się tam udział pyłków drzew spowodowany najpewniej wkraczaniem lasów na tereny uprawne (Jöns, Müller-Wille 2015, s. 218-220). Sytuacja ta zmieniła się w początkach VIII stulecia - spadł udział pyłku drzew najpewniej w wyniku pozyskiwania pól uprawnych, na obszarach zasiedlanych przez nowych osadników. Wyniki analiz materiałów archeologicznych i prób przyrodniczych skłoniły niektórych badaczy do wniosku, że pomiędzy zanikiem kultur o cechach późnorzymskich a pojawieniem się społeczności, które bezsprzecznie wiązać można ze Słowianami, istnieje słabo jeszcze rozpoznane ogniwo pośrednie (Schuster 2017, s. 42-49).

$\mathrm{Na}$ południowym pobrzeżu Bałtyku procesy osadnicze w początkach średniowiecza mogły przebiegać niejednolicie. Na środkowe Pomorze, na obszar zajmowany przez ludność grupy dębczyńskiej, pierwsze grupy Słowian mogły dotrzeć u schyłku VI w. tworząc w następnym stuleciu rozległą wspólnotę terytorialną 


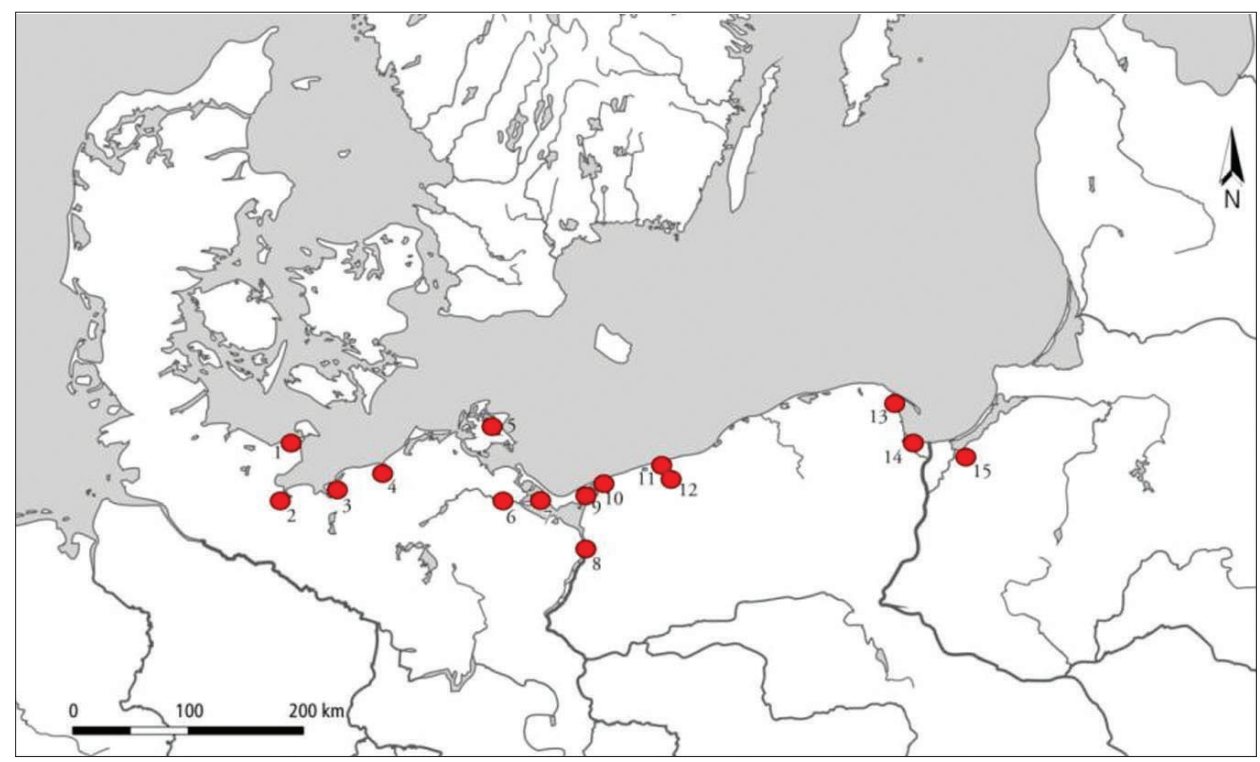

Ryc. 1. Osiedla rzemieślniczo-handlowe na południowym wybrzeżu Bałtyku:

1 - Stargard Oldenburg; 2 - Alt Lübeck; 3 - Groß Strömkendorf; 4 - Rostock-Dierkow; 5 - Ralswiek; 6 - Menzlin; 7 - Usedom; 8 - Szczecin; 9 - Wolin; 10 - Kamień Pomorski; 11 - Kołobrzeg; 12 - Bardy/Świelubie; 13 - Puck; 14 - Gdańsk; 15 - Janów Pomorski, za: Jöns, Messal 2013

z punktem centralnym w Białogardzie (Cnotliwy 1999, s. 75; 2005, s. 271; Łosiński 2008, s. 68-71), podobnie jak na dolnym nadodrzu i na Równinie Pyrzycko-Stargardzkiej. Na terenach położonych na zachód od Odry również natrafiono na osadnictwo słowiańskie pokrywające się z osadami z późnego okresu wędrówek ludów, na przykład w okolicy jeziora Teterow (Jöns, Müller-Wille 2015, s. 205-208). Znalezisko złotego brakteata z 1. połowy VI w. sugeruje, że lokalna społeczność miała kontakty ze Skandynawią. Spektakularnych danych dotyczących obecności Skandynawów we wschodniej części pobrzeża dostarczyły studia nad schyłkiem starożytności w pobliżu Elbląga. W VI-VII w. żyjąca tam ludność utrzymywała bliskie kontakty ze Skandynawią, zwłaszcza z Danią. Współwystępowanie przedmiotów luksusowych z codziennymi pozwala rozpatrywać obecność obcych wyrobów nie tylko w kategoriach ,importów”. Ocena charakteru kultury materialnej grupy elbląskiej prowadzi do wniosku, że wczesnośredniowieczne emporium Truso w dzisiejszym Janowie Pomorskim może być starsze niż dotychczas sądzono. Osada z okresu wędrówek ludów mogła być fundamentem emporium typowego dla wikingów założonego pod koniec VIII wieku (Bogucki 2013).

Konkretne przykłady interakcji słowiańsko-skandynawskich na południowym wybrzeżu Bałtyku w VIII-XI w. to 15 znanych obecnie osiedli rzemieślniczo-handlowych usytuowanych pomiędzy Limes Saxoniae a ujściem Wisły (ryc. 1). Na stan ich zachowania oraz charakter przeprowadzonych badań złożyło się wiele 
czynników, wśród których najważniejszy jest sposób zagospodarowania po upadku emporiów. Niektóre zostały opuszczone w średniowieczu, jak Groß Strömkendorf, Rostock-Dierkow, Menzlin, Bardy/Świelubie i Janów Pomorski, i wciąż możliwe jest przeprowadzanie $w$ ich obrębie różnorodnych badań nieinwacyjnych i wykopaliskowych. Inne, takie jak Ralswiek, Wolin, Szczecin, Kołobrzeg, funkcjonowały i rozwijały się nieprzerwanie do dzisiaj. Struktury wczesnośredniowieczne odkrywane są w ograniczonych przestrzennie wykopach i nie ma możliwości przeprowadzenia szerszych badań. Drugi nie mniej istotny element wspomniany we wstępie to zmiany warunków środowiskowych prowadzące do zalewania obszarów przybrzeżnych i zamulania dawnych przystani (Jöns, Messal 2013, Karle i in. 2015).

Z większości tych miejsc handlu i rzemiosła oraz ich okolic pochodzą, odkrywane podczas wykopalisk i prospekcji terenowych, liczne przedmioty obrazujące skalę i charakter powiązań dalekosiężnych. Ze wszystkich wspomnianych miejsc znane są wyroby rzemieślnicze, takie jak bazaltowe kamienie żarnowe, paciorki i naczynia szklane, obce wyroby ceramiczne, osełki fyllitowe, naczynia ze steatytu, wagi i odważniki wskazujące, że osiedla te były ogniwami w rozległej sieci powiązań handlowych, które dobrze widoczne są także w ośrodkach znacznie oddalonych od wybrzeża, na przykład w kompleksach osadniczych w Kałdusie i w Żółtym, gdzie znaleziono wiele przedmiotów wykonanych w stylu skandynawskim lub zgodnie ze skandynawską tradycją. Kwestią wciąż dyskutowaną jest pytanie, czy powstanie tych kompleksów jest wynikiem akulturacji lokalnych elit, czy może świadectwem fizycznej obecności obcej etnicznie ludności w środowisku słowiańskim (Chudziak, Kaźmierczak 2015).

W ciągu ostatniej dekady na obszarach położonych na zachód od Odry niezmiernie wzrosła liczba przedmiotów łączonych ze Skandynawami, i to zarówno ze stanowisk dobrze znanych i rozpoznanych archeologicznie, jak i nowych, wcześniej niedostarczających tego typu znalezisk. Zjawisko to jest konsekwencją ścisłej współpracy pomiędzy służbami ochrony dziedzictwa kulturowego a ochotnikami działającymi na zasadzie wolontariatu, którzy dysponują wykrywaczami metalu i wykorzystują je do systematycznych badań na stanowiskach archeologicznych w Meklemburgii i Szlezwiku-Holsztynie w ramach specjalnie dla tego celu opracowanego programu (Fischer 2010; Ruchhöft, Schirren 2010). Wyniki poszukiwań są systematycznie wprowadzane do obiegu naukowego w czasopismach i artykułach (Jahrbuch 2014; Biermann 2009; Schirren 2015). Wartość historyczna tych przedmiotów jest niezaprzeczalna, ale nie przybliża do rozwiązania problemu fizycznej obecności skandynawskich osadników na osiedlach słowiańskich dyskutowanego w literaturze przedmiotu.

Jednoznaczne w swojej wymowie są natomiast konstrukcje grobów i pozostałości budynków mieszkalnych odzwierciedlających skandynawskie tradycje, które zidentyfikowane zostały na południowym wybrzeżu Bałtyku. Można przypuszczać, że ludność żyjąca w diasporze organizowała swoje życie gospodarcze, społeczne 
i kulturowe w sposób, do jakiego była przyzwyczajona w swoich skandynawskich ojczyznach. Przyjmując takie założenie, należy wziąć pod uwagę obecność społeczności skandynawskich w Groß Strömkendorf, Menzlinie, Ralswiku, Usedom oraz Bardach/Świelubiu, gdzie odkryto groby i/lub pozostałości osadnicze całkowicie różne od słowiańskich.

Rozległe badania wykopaliskowe przeprowadzono w Groß Strömkendorf w latach 1995-1999 w ramach interdyscyplinarnego projektu badawczego, w obrębie osiedla i cmentarzyska rozciągającego się na północ od osady (Müller-Wille 2009). $\mathrm{Na}$ podstawie analizy źródeł archeologicznych i licznych dendrodatowań drewna z konstrukcji studni zrębowej, początki osady wydatowano na 2. ćwierć VIII w., a jej opuszczenie na 2. ćwierć IX stulecia (Tummuscheit 2011). Na terenie przylegającym bezpośrednio do linii brzegowej odkryto półziemianki (niem. Grubenhäuser, ang. pit-houses) usytuowane w sposób sugerujący planową organizację przestrzeni już na początku 2. połowy VIII wieku. Konstrukcja tych obiektów była zbliżona do znanych z Jutlandii, wysp duńskich i Skanii. Astrid Tummuscheit (2011, s. 91-97) uważa, że zostały zbudowane przez społeczność przesiąkniętą tradycjami budowlanymi tych regionów. W wypełniskach półziemianek znaleziono między innymi kości ryb, wśród których wyjątkowo wysoki procent stanowiły pozostałości dorsza, podobnie jak na licznych stanowiskach w południowej Skandynawii (Schmölcke 2004, s. 129; Schmölcke, Jöns 2013). Przekonujących danych co do obecności Skandynawów nad Zatoką Wismarską dostarczyły badania cmentarzyska. Odkryto na nim pochówki szkieletowe i ciałopalne pod kurhanami (Gerds 2006). Różnorodność form pochówków świadczy o przywiązaniu do różnych tradycji pogrzebowych, a analizy antropologiczne szkieletów i skremowanych kości wykazały, że w niektórych przypadkach mamy do czynienia z pochówkami członków rodziny (Wolf 2015). Charakterystyczne dla kultury skandynawskiej są pochówki w jakiś sposób powiązane z łodziami (Müller-Wille 1995; Jöns 2009), z bliskimi analogiami w południowo-zachodniej Norwegii, środkowej Szwecji i południowej Finlandii (Gerds 2015, s. 97-98). W południowej strefie Bałtyku groby łodziowe odkryto również w Ralswieku (Herrmann, Warnke 2008), Usedom (Biermann 2004) i Rusinowie na Pomorzu (Filipowiak 1989, s. 711; Duczko 1997, s. 204). Do pochówków z różnych części południowej Skandynawii można też porównać pochówki szkieletowe, w których zmarły leżał na boku w skulonej pozycji, oraz niektóre ciałopalne. Wszystkie te przesłanki skłoniły do wniosku, że znaczną część populacji emporium w Groß Strömkendorf stanowili Skandynawowie (Gerds 2015, s. 225-230). Do podobnych wniosków doprowadziły ponadto analizy ceramiki naczyniowej (Brorsson 2010). Ustalono, że 23\% naczyń nie pochodzi z lokalnych pracowni, ale z kilku regionów w północnej Europie - największy udział $\mathrm{w}$ tej grupie miała ceramika $\mathrm{z}$ południowej Skandynawii, tj. 5\% (Brorsson, Jöns 2010).

Obecność osadników ze Skandynawii, porównywalną z Groß Strömkendorf, stwierdzono na osiedlu rzemieślniczo-handlowym w Menzlin nad Pianą, zlokali- 
zowanym w odległości $8 \mathrm{~km}$ od wybrzeża, na północnym brzegu rzeki. Na kompleks osadniczy składa się osada z półziemiankami oraz cmentarzysko. W pobliżu miejsc zamieszkania dokonywano również napraw statków, o czym świadczą liczne znaleziska charakterystycznych elementów szkutniczych wybagrowanych z Piany (Jöns 2005). Stanowisko w Menzlin nie było objęte większym projektem badawczym, ale w latach 60. wykonano szereg wykopalisk archeologicznych, a w latach 90. i na początku XXI w. badania geofizyczne i podwodne (zbiorczo: Kleingärtner 2014, s. 346-450). Opierając się na datowaniu dendrochronologicznym konstrukcji zrębowej oraz analizie typologiczno-chronologicznej ceramiki i przedmiotów metalowych, początki osiedla wydatowano na 1. połowę VIII w., koniec zaś jego funkcjonowania na początek X stulecia. $\mathrm{Z}$ dotychczasowego rozpoznania wynika, że osadnictwo objęło obszar około 10 ha. Badania geomagnetyczne i wyniki badań archeologicznych z lat 60. pozwalają sądzić, że osiedle miało strukturę podobną do odkrytej w Groß Strömkendorf. Obiekty mieszkalne i gospodarcze były sytuowane wzdłuż dróg (Schoknecht 1977). Odkryto pozostałości pracowni kowalskich i grzebienniczych oraz miejsca odlewu brązu i produkcji paciorków bursztynowych oraz szklanych. Wśród wyrobów znaczną część stanowiły przedmioty obcego pochodzenia. Bezpośrednio na wschód od osady odkryto cmentarzysko założone w początkach IX stulecia. Badania geofizyczne i skaning laserowy wykazały, że cmentarzysko zajmowało powierzchnię około 3 ha. Do tej pory przeprowadzono na nim jedynie skromne wykopaliska, ale odkryto między innymi grób łodziowy i pochówki w obstawach kamiennych tworzących kształt łodzi, na wzór grobów z cmentarzysk wikińskich znanych z południowej Skandynawii (Capelle 1986; Müller-Wille 1995, s. 103). Warto zwrócić uwagę na fakt, że wszystkie odkryte dotąd urny popielnicowe były typowymi naczyniami słowiańskimi zaliczanymi do grupy Feldberg (Jöns 2009, 175; Kleingärtner 2014, s. 102-111).

Na południe od osiedla rzemieślniczo-targowego odkryto pozostałości drogi z nawierzchnią kamienną, zbudowaną w 1. połowie IX wieku. Miała ona kontynuację po obu stronach Piany, przez most (Schoknecht 1992; Kleingärtner 2014, s. 367-369), który powstał w początkach 2. połowy VIII wieku (Jöns 2005, s. 97). Konstrukcję tę odkryto na odcinku o długości około $800 \mathrm{~m}$. Użycie kamieni jako budulca nawierzchni nie było w zwyczaju Słowian zachodnich. Wiele przykładów w ten sposób wznoszonych dróg pochodzi z Danii i Szwecji (Ambrosiani 1973, s. 15, Abb. 6; Schou Jørgensen 1988; Crumlin-Pedersen i in. 1992, s. 46 i n.; Ravn 1999, s. 248 i n.).

Obecność przedstawicieli ludów Północy odnotowano także w obrębie nadparsęckiego kompleksu osadniczego znanego w literaturze przedmiotu jako Bardy/ Świelubie, składającego się z grodu, cmentarzyska i odkrytej niedawno obwarowanej osady. Dzięki wykopaliskom ustalono, że umocnienia rozległego grodu na skraju wyniesienia powstały na pozostałościach osadnictwa otwartego z obiektami mieszkalnymi w typie półziemianek, które na podstawie ceramiki wydatowane zostały na VIII stulecie. Do końca IX w. funkcjonował pierwszy (starszy) człon 
grodu w Bardach w otoczeniu osad otwartych położonych nad krawędzią doliny Parsęty. Na przełomie IX/X w. gród i otaczające go osiedla podgrodowe zlikwidowano (Łosiński 1994). U schyłku VIII i w początkach IX stulecia mieszkańcy grodu aktywnie uczestniczyli $\mathrm{w}$ wymianie dalekosiężnej rozwijającej się $\mathrm{w}$ tym czasie w strefie nadbałtyckiej.

Z grodem w Bardach związane jest rozległe cmentarzysko kurhanowe złożone z około 100 kopców, w literaturze znane jako Świelubie, z grobami przeważnie ciałopalnymi, niekiedy szkieletowymi, o zróżnicowanym wyposażeniu, które funkcjonowało od 2. ćwierci IX do końca tego stulecia. Na wyposażenie grobowe przebadanych pochówków składały się między innymi złote, srebrne i brązowe ozdoby stroju, w tym fibule z analogiami ze stanowisk w środkowej Szwecji i Gotlandii datowane na VIII-IX wiek. Podobnie jak w przypadku Menzlina i Gross Strömkendorf można sądzić, że również w Świelubiu pochowano całe rodziny skandynawskich osadników (zbiorczo Łosiński 2008). Dopiero jednak w ostatnich latach, dzięki włączeniu kompleksu nad Parsętą do interdyscyplinarnego programu badawczego, odkryto pozostałości emporium założonego bezpośrednio nad rzeką. $\mathrm{Na}$ jego obszarze, po likwidacji grodu bardzkiego, w X w. wzniesiono niewielki gródek znany w literaturze jako gród w Świelubiu. Na ostateczne wyniki badań archeologicznych prowadzonych w latach 2014-2016 trzeba jeszcze poczekać. Już dziś wiadomo jednak, że emporium założone zostało $\mathrm{w}$ okresie wznoszenia starszego członu grodu w Bardach pod koniec VIII - w początkach IX stulecia. Terminus post quem wyznaczają dendrodaty próbek drewna pobranych $\mathrm{z}$ umocnień osady: po $701 \mathrm{r}$. (bez możliwości dokładniejszego datowania ze względu na niekompletność przyrostów) (por. Kowalska, Messal 2017) oraz datowanie kilku ułamków dirhamów arabskich odkrytych w najstarszej warstwie osadniczej, zawierające się pomiędzy latami 775-785 a 813-833 (Malarczyk 2017).

Silne związki Skandynawów ze Słowianami w początkach średniowiecza stwierdzono także u ujścia Wisły. Intensywne badania w Janowie Pomorskim prowadzone od lat 80. pozwoliły na utożsamienie odkrytej osady z Truso (Jagodziński 2010; Brather, Jagodziński 2012). Opierając się na specyficznym typie budownictwa oraz analizie źródeł ruchomych, które niemal w całości uznane zostały za skandynawskie, Marek Jagodziński (2009, s. 184) uznał, że osiedle było zamieszkane głównie przez Skandynawów.

Problem interakcji słowiańsko-skandynawskich we wczesnym średniowieczu to zagadnienie złożone, wielokrotnie poruszane $\mathrm{w}$ literaturze przedmiotu, świetnie podsumowane przez Władysława Łosińskiego (2008, s. 143-169; tam obszerna literatura). Od czasu publikacji Jego rozważań przybyło wiele nowych informacji pozwalających na uściślenie niektórych kwestii, zwłaszcza związanych z bliskim Mu rejonem nadparsęckim. Odkrycie materialnych pozostałości emporium w Świelubiu, którego istnienia domyślano się od dawna, jest początkiem dalszych badań. Skromne na razie badania wykopaliskowe ujawniły istnienie umocnień, przynajmniej półkolistych oraz nawarstwień osadniczych z obiektami mieszkalnymi i go- 
spodarczymi. Ważnym osiągnięciem jest pozyskanie prób drewna do dendrodatowań, pierwszych dla tego obszaru. Poszerzył się także zbiór monet arabskich ułatwiający datowanie post quem odkrytych struktur oraz przedmiotów związanych z wymianą dalekosiężną, w tym paciorków szklanych. Dane te uściślają dotychczasowe wnioskowanie na temat funkcjonowania kompleksu osadniczego w Bardach/Świelubiu w systemie powiązań gospodarczych i społecznych we wczesnym średniowieczu.

\section{LITERATURA}

Ambrosiani B. 1973, Fältarbete, konstruktioner, stratigrafi och datering, w: B. Ambrosiani (red.), Birka. Svarta Jordens Hamnområde: arkeologisk undersökning 1970-1971, Riksantikvarieämbetet Rapport $\mathrm{C} 1$, Stockholm.

Biermann F. 2004, Usedomer Bootsgräber, „Germania“ 82, s. 159-176.

- 2009, Von Gotland nach Vorpommern - Skandinavische Funde aus Nonnendorf, Lkr. Ostvorpommern. Archäologische Entdeckungen in Mecklenburg-Vorpommern. Kulturlandschaft zwischen Recknitz und Oderhaff, „Archäologie in Mecklenburg-Vorpommern” 5, s. 167-168.

Bogucki M. 2013, Before the Vikings. Foreigners in the lower Vistula region during the Migration Period and the origins of Truso, w: S. Moździoch, B. Stanisławski, P. Wiszewski (red.), Scandinavian Culture in Medieval Poland, Interdysciplinary Medieval Studies 2, Wrocław, s. 81-111.

Brather S., Jagodziński M. 2012, Der wikingerzeitliche Seehandelsplatz von Janów (Truso). Geophysikalische, archäopedologische und archäologische Untersuchungen 2004-2008, „Zeitschrift für Archäologie des Mittelalters" 24.

Brorsson T. 2010, The pottery from the Early Medieval Trading Site and Cemetery at Groß Strömkendorf, Lkr. Nordwestmecklenburg, Frühmittelalterliche Archäologie zwischen Ostsee und Mittelmeer 1. Forschungen zu Groß Strömkendorf 3, Wiesbaden.

Brorsson T., Jöns H. 2010, Analyses of the ceramic material from the emporium reric near Gross Strömkendorf, Mecklenburg, w: B. Ramminger, O. Stilborg, M. Helfert red., Naturwissenschaftliche Analysen vor- und frühgeschichtlicher Keramik I. Methoden, Anwendungsbereiche, Auswertungsmöglichkeiten. Universitätsforschungen zur Prähistorischen Archäologie 176, s. 75-86.

Capelle T. 1986, Schiffssetzungen, „Prähistorische Zeitschrift“ 61, s. 1-63.

Chudziak W. 2013, Remarks on particular material traces os Scandinavian culture in Pomerania, w: S. Moździoch, B. Stanisławski, P. Wiszewski (red.), Scandinavian culture in Medieval Poland, Wrocław, s. 151-178.

Chudziak W., Kaźmierczak R. (red.) 2015, The Island in Żótte on Lake Zarańskie. Early Medieval Gateway into West Pomerania, Torun.

Cnotliwy E. 1999, Białogard i okolice we wczesnym średniowieczu, w: B. Polak (red.), Biatogard 1299-1999. Studia z dziejów miasta, Koszalin, s. 71-93.

Cnotliwy E. 2005, Pierwsze dendrodaty z białogardzkiego grodziska, „Folia Praehistorica Posnanienses” 13/14, s. 271-278.

Crumlin-Pedersen O., Schou Jørgensen M., T. Edgren 1992, Skibe og samfcerdsel, w: E. Roesdahl (red.), Viking og Hvidekrist. Norden og Europa 800-1200, Ausstellungskatalog Kopenhagen, Kopenhagen, s. $42-51$.

Duczko W. 1997, Scandinavians in the Southern Baltic between the 5th and the 10th centuries A.D., w: P. Urbańczyk red., Origins of Central Europe, Warszawa, s. 129-135.

Dulinicz M. 2001, Ksztaltowanie się Stowiańszczyzny Pólnocno-Zachodniej. Studium archeologiczne, Warszawa.

Filipowiak W. 1989, Handel Und Handelsplätze an der Ostseeküste Westpommerns, „Bericht der Römisch-Germanischen Komission“ 69, s. 690-719. 
Fischer J. 2010, Die Detektorgruppe des Archäologischen Landesamtes Schleswig-Holstein. Eine Bilanz nach fünf Jahren, „Arkæologi i Slesvig/Archäologie in Schleswig“ 13, s. 9-18.

Gerds M. 2006, Scandinavian burial rites on the southern Baltic coast. Boat graves in cemeteries of early medieval trading places, w: A. Andrén, K. Jennbert, C. Raudvere, (red.), Old Norse religion in long-term perspectives. Origins, changes, and interactions. An international conference in Lund, Sweden, June 3-7, 2004, Vägar till Midgård 8, Lund, s. 153-158.

- 2015, Das Gräberfeld des frühmittelalterlichen Seehandelsplatzes von Groß Strömkendorf, Lkr. Nordwestmecklenburg, Frühmittelalterliche Archäologie zwischen Ostsee und Mittelmeer, vol. 6. Forschungen zu Groß Strömkendorf 5, Wiesbaden.

Herrmann J., Warnke D. 2008, Die slawisch-wikingischen Siedlungen und deren Hinterland. Teil V-Das Hügelgräberfeld in den „, Schwarzen Bergen“ bei Ralswiek, Schwerin.

Jagodziński M. 2009, The settlement of Truso, w: A. Englert, A. Trakadas (red.), Wulfstan's Voyage. The Baltic Sea region in the early Viking Age as seen from shipboard, Roskilde, s. 182-197.

- 2010, Truso. Między Weonodlandem a Witlandem, Elbląg.

Jahrbuch 2014, „Jahrbuch Bodendenkmalpflege in Mecklenburg-Vorpommern“.

Jöns H. 2005, Zur Rekonstruktion der historischen Topographie und Infrastruktur des Handelsplatzes Menzlin an der Peene, „Jahrbuch Bodendenkmalpflege in Mecklenburg-Vorpommern“ 53, s. 81-109.

- 2009, Ports and emporia of the southern coast: from Hedeby to Usedom and Wolin, w: A. Englert, A. Trakadas (red.), Wulfstan's Voyage. The Baltic Sea region in the early Viking Age as seen from shipboard, Roskilde, s. 160-181.

- 2011, Settlement development in the shadow of coastal changes - case studies from the Baltic rim, w: J. Harff, S. Björck, P. Hoth (red.), The Baltic Sea basin, Berlin-Heidelberg, s. 301-336.

Jöns H., Messal S. 2013, Neue Forschungen zur Struktur mittelalterlicher Hafenanlagen an der südlichen Ostseeküste, w: M. Bogucki, M. Rębkowski (red.), Economies, Monetisation and Society in West Slavic Lands 800-1200 AD, Wolińskie Spotkania Mediewistyczne 2, Szczecin, s. 25-43.

Jöns H., Müller-Wille M. 2015, The early phase of Slavic settlement in the south-western Baltic coastal area - current research in the area between the Bay of Kiel and the Oder River, "Archaeologia Polona" 48, s. 197-228.

Karle M., Messal S., Wolters S. 2015, Early Medieval emporia and their ports in the south-western Baltic Sea, Siedlungs- und Küstenforschung im südlichen Nordseegebiet 38, s. 239-255.

Kleingärtner S. 2014, Die frühe Phase der Urbanisierung an der südlichen Ostseeküste im ersten nachchristlichen Jahrtausend, Studien zur Siedlungsgeschichte und Archäologie der Ostseegebiete 13, Neumünster.

Kowalska A., Messal S. 2017, Die archäologischen Arbeiten in Świelubie 2015/2016, „Materiały Zachodniopomorskie" 13, s. 243-252.

Latałowa M. 2017, Przyrodnicze ślady przemian osadniczych między Odra a Wisła w I tysiącleciu po Chr./Natural evidence of settlement changes between the Odra and the Vistula in the first millennium AD, w: A. Bursche, K. Kowalski, B. Rogalski (red.), Barbarzyńskie tsunami. Okres Wędrówek Ludów w dorzeczu Odry $i$ Wisty/ Barbarian tsunami. Migration Period between the Odra and the Vistula, Szczecin, s. 17-24.

Leciejewicz L. 2000, Nowa postać świata. Narodziny średniowiecznej cywilizacji europejskiej, Wrocław.

Łosiński W. 1994, W sprawie genezy osiedli wczesnomiejskich u Słowian nadbałtyckich, „Slavia Antiqua" 35 , s. 101-128.

- 2008, Pomorze Zachodnie we wczesnym średniowieczu. Studia archeologiczne, Poznań.

Malarczyk D. 2017, Monety islamskie ze Świelubia, maszynopis w archiwum Działu Archeologii Muzeum Narodowego w Szczecinie.

Mangelsdorf G. 2001, Die Drachenfibel von Nehringen und das Problem der Vendelzeit in Vorpommern, w: M. Meyer (red.), “...trans Albim Fluvium”. Forschungen zur vorrömischen, kaiserzeitlichen und mittelalterlichen Archäologie. Festschrift A. Leube, Internationale Archäologie, Studia Honoraria 10, Rahden/Westf, s. 493-504.

Müller-Wille M. 1995, Boat-Graves. Old and New Views, w: O. Crumlin-Pedersen, B. Munch Thye red., The Ship as Symbol in Prehistoric and Medieval Scandinavia, Copenhagen, s. 101-110. 
- 2009, Emporium reric, w: S. Brather, D. Geuenich, Ch. Huth (red.), Historia archaeologica. Festschrift für Heiko Steuer zum 70. Geburtstag, Reallexikon der Germanischen Altertumskunde Ergänzungsband, Band 70, Berlin-New York, s. 453-473.

Ravn M. 1999, Nybro. En trcevej fra Kong Godfreds tid, "Kuml", s. 227-255.

Ruchhöft F., Schirren M.C. 2010, Münzen, Schmuck und Silberbarren, „Archäeologie in Deutschland“ 6, s. 4-5.

Schirren M.C. 2015, Eine Gotländerin in der Uckermark...? Zu neu entdeckten tierkopfförmigen Fibeln der späten Wikingerzeit in Vorpommern und anderen Objekten gotländischer Provenienz, „Archäologische Berichte aus Mecklenburg-Vorpommern“ 22, s. 29-40.

Schmölcke U. 2004, Nutztierhaltung, Jagd und Fischfang. Zur Nahrungsmittelwirtschaft des frühgeschichtlichen Handelsplatzes von Groß Strömkendorf, Landkreis Nordwestmecklenburg, Forschungen Groß Strömkendorf 1. Beiträge zur Ur- und Frühgeschichte Mecklenburg-Vorpommerns 43, Lübstorf.

Schmölcke U., Jöns H. 2013, Livestock in Early Medieval Ports of Trade on the Baltic Sea: The Emporium Reric and other Northern German Sites, w: S. Kleingartner, T.P. Newfield, S. Rossignol, D. Wehner (red.), Landscapes and Societies in Medieval Europe East of the Elbe: Interactions between Environmental Settings and Cultural Transformations, Papers in Medieval Studies" 23, 54-72.

Schoknecht U. 1977, Menzlin, ein frühgeschichtlicher Handelsplatz an der Peene, „Beiträge zur Ur- und Frühgeschichte der Bezirke Rostock, Schwerin und Neubrandenburg“ 10, Berlin.

- 1992, Eine Straße der Wikinger bei Menzlin, „Archäologie in Deutschland“ 1992:1, s. 51.

- 2001, Mögliche Kontakte zwischen Germanen und Slawen in Mecklenburg, w: M. Meyer red., “... trans Albim Fluvium”. Forschungen zur vorrömischen, kaiserzeitlichen und mittelalterlichen Archäologie. Festschrift A. Leube, Internationale Archäologie, Studia Honoraria 10. Rahden/Westf, s. 511-516.

Schou Jørgensen M. 1988, Vej, vejstrøg og vejspcerring. Jernalders landfcerdsel, w: P. Mortensen, B. Rasmussen (red.), Jernalderens stammessamfund. Fra Stamme til Stat i Danmark 1, Jysk Arkaeologisk Selskabs Skrifter 22:1, s. 101-106.

Schuster J. 2017, Wiek V. Czas wielkich zmian/Fifth century. The time of great change, w: A. Bursche, K. Kowalski, B. Rogalski (red.), Barbarzyńskie tsunami. Okres Wędrówek Ludów w dorzeczu Odry $i$ Wisty/ Barbarian tsunami. Migration Period between the Odra and the Vistula, Szczecin, s. 41-49.

Tummuscheit A. 2011, Die Baubefunde des frühmittelalterlichen Seehandelsplatzes von Groß Strömkendorf, Lkr. Nordwestmecklenburg, Frühmittelalterliche Archäologie zwischen Ostsee und Mittelmeer 2, Wiesbaden.

Wolf M. 2015, Groß Strömkendorf - Reric: die Menschen und ihre Lebensumstände. Forschungen zu Groß Strömkendorf 5. Frühmittelalterliche Archäologie zwischen Ostsee und Mittelmeer 6. Wiesbaden. 